J. Appl. Glycosci., 51, 51-54 (2004)

(C) 2004 The Japanese Society of Applied Glycoscience

Note (in Japanese with English Abstract)

\title{
Analysis of Amylose Chain Lengths Forming Complexes with Lysophosphatidylcholines
}

(Received June 26, 2003 ; Accepted September 12, 2003)

\author{
Masatsugu Yamashita, ${ }^{1, *}$ Hajime Taniguchi, ${ }^{2}$ Satoru Onogi ${ }^{3}$ and Makoto Hisamatsu ${ }^{3}$ \\ 'Taiyo Kagaku Central Research Laboratories \\ (1-3, Takara-machi, Yokkaichi 510-0844, Japan) \\ ${ }^{2}$ Department of Biological Chemistry, Chubu University \\ (1200, Matsumoto-cho, Kasugai 487-8501, Japan) \\ ${ }^{3}$ Faculty of Bioresources, Mie University \\ (1515, Kamihama, Tsu 514-8507, Japan)
}

\begin{abstract}
The formation of amylose complexes with eight lysophosphatidylcholines; 1-capryl lysophosphatidylcholine (LPC-C 10 : 0), 1-lauroyl LPC (LPC-C 12 : 0), 1-myristoyl LPC (LPC-C 14 : 0), 1-palmitoyl LPC (LPC-C 16 : 0), 1-stearoyl LPC (LPC-C 18 : 0), 1-oleoyl LPC (LPC-C 18 : 1), 1-linoleoyl LPC (LPC-18 : 2) and 1-arachidoyl LPC (LPC-C 20 : 0), was conducted in aqueous solution using a commercial amylose with an average degree of polymerization (DP) of 18. The chain distributions of amylose precipitated by forming a complex in aqueous solution $\left(2^{\circ} \mathrm{C}\right)$ were analyzed by high-performance anion exchange chromatography with a pulsed amperometric detector (HPAEC-PAD). The smallest DPs of amylose forming complexes with LPC-C 14 : 0, LPC-C 16 : 0, LPC-C 18 : 0, LPC-C $18: 1$, LPC-18 : 2 and LPC-C $20: 0$ were DP 27, DP 29, DP 29, DP 31, DP 31 and DP 35, respectively. The principal amylose chains found in complexes with LPC-C $14: 0$, LPC-C 16 : 0, LPC-C 18 : 0, LPC-C 18 : 1, LPC-18 : 2 and LPC-C 20 : 0 were DP 34-36, DP 32-34, DP 3335, DP 34-36, DP 36-38 and DP 36-38, respectively.
\end{abstract}

Key words: amylose complex, amylose-chain length, lysophosphatidylcholine

\section{リゾホスファチジルコリンと複合体を形成するアミロース鎖長の解析

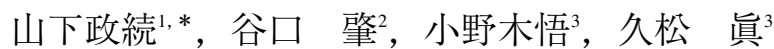 \\ '太陽化学株式会社総合研究所 (510-0844 四日市市宝町 1-3) \\ ${ }^{2}$ 中部大学応用生物学部 (487-8501 春日井市松本町 1200) \\ ${ }^{3}$ 三重大学生物資源学部（514-8507 津市上浜町 1515$)$}

米，トウモロコシ，小麦などの穀物種子の澱粉粒には， 主にオレイン酸, リノール酸などの不飽和脂肪酸から構成 されるリゾリン脂質, 遊離脂肪酸, 脂肪酸モノグリセリド などの内部脂質が含まれており, 澱粉と複合体を形成して いる ${ }^{1,2)}$. これらの脂質は, in vitro でもアミロース, 澱粉 と複合体を形成することが報告されている年年.

種々の平均重合度 $(\overline{\mathrm{DP}})$ のアミロースを用いた複合体 形成の実験により，飽和脂肪酸や脂肪酸モノグリセリドの 複合体形成に必要なアミロースの重合度を決定することが 試みられている ${ }^{5-8)}$. しかしながら，これまでの実験では単 一の重合度からなる高純度のアミロースを使用していない こと，また，複合体を構成するアミロース鎖長を分析して いないことにより，その包摂に必要なアミロースの重合度 は研究者によって異なっている ${ }^{5-10)}$. さらに, 穀物澱粉の 内部脂質として多く含まれているリゾリン脂質の複合体形 成に必要なアミロースの重合度に関してはこれまで報告さ

${ }^{*}$ Corresponding author $($ Tel. $+81-593-47-5413$, Fax. $+81-593-47-$ 5417, E-mail: myamashita@taiyokagaku.co.jp).

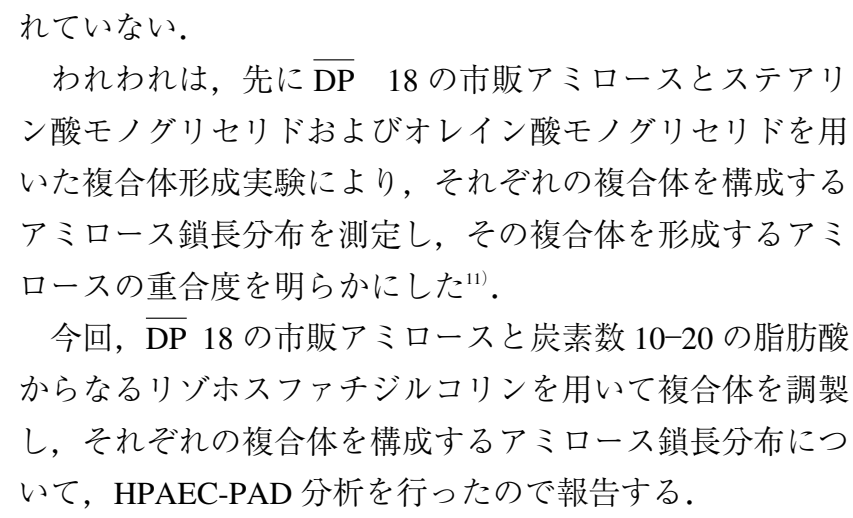

今回, $\overline{\mathrm{DP}} 18$ の市販アミロースと炭素数 10-20 の脂肪酸 からなるリゾホスファチジルコリンを用いて複合体を調製 し，それぞれの複合体を構成するアミロース鎖長分布につ いて, HPAEC-PAD 分析を行ったので報告する.

\section{実 験 方 法}

\section{1. 試料}

リゾホスファチジルコリン（LPC）は，フナコシ(株製の 1-カプリルリゾホスファチジルコリン（LPC-C 10：0，純 度 99\%)，1-ラウロイルリゾホスファチジルコリン（LPCC 12：0, 純度 99\%)，1-ミリストイルリゾホスファチジル コリン（LPC-C 14：0, 純度 99\%)，1-パルミトイルリゾホ 
スファチジルコリン（LPC-C 16：0，純度 99\%），1-ステア ロイルリゾホスファチジルコリン（LPC-C 18：0，純度 99\%)，1-オレオイルリゾホスファチジルコリン（LPC-C $18: 1$, 純度 99\%), 1-リノレオイルリゾホスファチジルコ リン（LPC-C $18 ： 2$, 純度 94\%), 1-アラキドイルリゾホス ファチジルコリン（LPC-C 20：0，純度 99\%）を用いた.

アミロースはトウモロコシ由来の(株)林原生物化学研究所 の商品名：アミロース $\mathrm{EX}-1(\overline{\mathrm{DP}} 18$, 粗タンパク : $0.02 \%$, 水分：7.90\%）を用いた。

水酸化カリウム, 塩酸, 水酸化ナトリウム, 酢酸ナトリ ウムは和光純薬工業(株)の特級試薬をそのまま用いた。水は 蒸留水を用いた。

\section{2. アミロース-脂質複合体の調製}

1）アミロース水溶液の調製

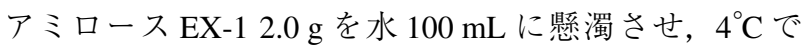
1 晚放置しアミロースを膨潤させた。その後, $1 \mathrm{M}$ 水酸化 カリウム $100 \mathrm{~mL}$ を加え, $1 \mathrm{M}$ 塩酸で $\mathrm{pH} 6.0$ に調整し, 水 で $1000 \mathrm{~mL}$ に定容して $0.2 \%(\mathrm{w} / \mathrm{v})$ アミロース水溶液を 得た。

\section{2）複合体の調製}

ビーカー $(50 \mathrm{~mL})$ に入れた $0.16 \mathrm{~mol}$ に相当する各 LPC (66-88 mg) に水 $50 \mathrm{~mL}$ を加え, $60^{\circ} \mathrm{C}$ で 30 分間攪拌し分 散溶解させてそれぞれの水溶液を調製した. この水溶液を $0.2 \%(\mathrm{w} / \mathrm{v})$ アミロース水溶液 $250 \mathrm{~mL}$ に加え, $60^{\circ} \mathrm{C}$ で 30 分間，ときどき攪拌した. $2^{\circ} \mathrm{C}$ まで水冷し， 2 時間放置し た後, $8000 \mathrm{~g}$ で 20 分間遠心分離し, 沈澱物（複合体）を 沈降させた。上澄み液を注意深くデカンテーションにより 除去した後, 沈澱物に $20^{\circ} \mathrm{C}$ の水 $300 \mathrm{~mL}$ を加えて攪拌し ながら $60^{\circ} \mathrm{C}$ まで昇温することにより沈澱物を水洗した後, $2{ }^{\circ} \mathrm{C}$ まで水冷し， 2 時間放置し， $8000 \times g$ で 20 分間遠心分 離し, 沈澱物を沈降させた。この操作を 2 回行った. 沈澱 物を回収し, 凍結乾燥して LPC-アミロース複合体の粉末 （A）を得た．遠心分離後の上清部をあつめて凍結乾燥する ことにより複合体を形成しなかった LPC とアミロースの 混合粉末 $(\mathrm{B})$ を得た。

また，コントロールとして水 $50 \mathrm{~mL}$ を $0.2 \%(\mathrm{w} / \mathrm{v})$ ア ミロース水溶液 $250 \mathrm{~mL}$ に加え, $60^{\circ} \mathrm{C}$ で 30 分間, ときど き攪汼した後 $2^{\circ} \mathrm{C}$ まで水冷し, 2 時間放置し沈澱の有無を 観察した。

\section{DSC 測定}

銀製の $70 \mu \mathrm{L}$ 容量の密封型試料容器に，凍結乾燥した LPC-アミロース複合体粉末(A) $10 \mathrm{mg}$ に水 $40 \mathrm{mg}$ を加えて, セイコー電子工業(株製の示差走査熱量計 DSC-100を用い て昇温速度 $1.5^{\circ} \mathrm{C} / \mathrm{min} に 230^{\circ} \mathrm{C}$ から $130^{\circ} \mathrm{C}$ の範囲で $\mathrm{DSC}$ 測定を行った。また，遠心分離後の上清部の LPCとアミ ロースの混合粉末 $(\mathrm{B})$ および各 LPC についても，同様に測 定した. LPC-C 12：0のアミロース複合体粉末 $(\mathrm{A})$ は，そ の収量が非常に少なかったためにDSC 測定を行わなかっ た。

\section{HPAEC-PAD によるアミロース組成分析}

1） サンプル調製

凍結乾燥させた LPC-アミロース複合体粉末(A) $1 \mathrm{mg}$ に $1 \mathrm{M}$ 水酸化カリウム $150 \mu \mathrm{L}$ を加えて氷冷しながら攪拌し て溶解させた。 この溶液 $125 \mu \mathrm{L}$ に蒸留水 $125 \mu \mathrm{L}$ を加え, 遠 心分離 $\left(3000 \mathrm{rpm}, 10 \mathrm{~min}, 4^{\circ} \mathrm{C}\right)$ を行い, 上清 $3 \mu \mathrm{L}$ を HPAEC-PAD 分析に供した。

2） HPAEC-PAD装置およびカラム

HPAEC-PAD 分析装置には, Dionex BioLC system（Dionex 社製) を使用し，検出器にはパルスドアンペロメト リー検出器（Model PAD II）を用いた。 カラム：CarboPac PA 1 Column $(4 \times 250 \mathrm{~mm})$, 溶媒 A：150 mM 水酸化ナト リウム, 溶媒 B：150 mM 水酸化ナトリウム $+500 \mathrm{~mm}$ 酢酸 ナトリウムを用いて, 流速 $1 \mathrm{~mL} / \mathrm{min}$ で既報 ${ }^{11)}$ と同条件で 分析を行った。

\section{結 果 と考 察}

\section{1. 複合体の調製}

$\overline{\mathrm{DP}} 18$ のアミロース EX-1 と LPC の混合溶液は, $60^{\circ} \mathrm{C}$ では沈澱が形成されず，冷却すると約 $40^{\circ} \mathrm{C}$ から徐々に白 濁し沈澱が形成された. $2^{\circ} \mathrm{C}$ の沈澱物を凍結乾燥して得ら れた LPC-アミロース複合体の粉末(A)の収量（凍結乾燥重 量) を Table 1 に示した.アミロース EX-1の水溶液は沈 澱を生成しなかった。 LPC-C 10：0 とアミロース EX-1の 混合溶液は沈澱を生成しなかった. LPC-C $12: 0$ とアミ ロース EX-1の混合溶液は沈澱を微量生成した。脂質とア ミロースの複合体は，水不溶性で沈澱することが報告され ている ${ }^{3,8,11)}$. Table 1 の沈澱物の収量から, LPC-C 14:0 と LPC-C 16：0 はアミロース EX-1 と最もよく複合体を形成

Table 1. Yeilds of amylose-lysophosphatidylcholine complexes.

\begin{tabular}{lcc}
\hline \multicolumn{1}{c}{ Complex } & \multicolumn{1}{c}{ Abbreviation } & Yield (mg) \\
\hline Amylose-1-capryl lysophosphatidylcholine & LPC-C 10:0 Complex & 0 \\
Amylose-1-lauroyl lysophosphatidylcholine & LPC-C 12:0 Complex & 1.7 \\
Amylose-1-myristoyl lysophosphatidylcholine & LPC-C 14:0 Complex & 77.5 \\
Amylose-1-palmitoyl lysophosphatidylcholine & LPC-C 16:0 Complex & 76.1 \\
Amylose-1-stearoyl lysophosphatidylcholine & LPC-C 18:0 Complex & 70.6 \\
Amylose-1-oleoyl lysophosphatidylcholine & LPC-C 18:1 Complex & 48.4 \\
Amylose-1-linoleoyl lysophosphatidylcholine & LPC-C 18:2 Complex & 46.5 \\
Amylose-1-arachidoyl lysophosphatidylcholine & LPC-C 20:0 Complex & 59.8 \\
\hline
\end{tabular}


Table 2. Thermal properties of complexes of amylose-lysophosphatidylcholine.

\begin{tabular}{cccrc}
\hline Sample & $T_{\mathrm{o}}\left({ }^{\circ} \mathrm{C}\right)$ & $T_{\mathrm{p}}\left({ }^{\circ} \mathrm{C}\right)$ & $T_{\mathrm{c}}\left({ }^{\circ} \mathrm{C}\right)$ & $\Delta H(\mathrm{~J} / \mathrm{g})$ \\
\hline LPC-C 14 : 0 Complex & 67.3 & 82.0 & 92.1 & 7.7 \\
LPC-C 16 : 0 Complex & 77.0 & 89.6 & 99.5 & 6.6 \\
LPC-C 18 : 0 Complex & 78.1 & 95.0 & 108.4 & 5.5 \\
LPC-C 18 : 1 Complex & 72.7 & 89.8 & 99.5 & 8.8 \\
LPC-C 18 : 2 Complex & 65.0 & 81.5 & 100.6 & 11.6 \\
LPC-C 20 : 0 Complex & 85.4 & 98.9 & 107.2 & 4.2 \\
\hline
\end{tabular}

DSC analysis condition; sample, $10 \mathrm{mg}$; water, $40 \mathrm{mg}$; heating rate, $1.5^{\circ} \mathrm{C} / \mathrm{min}$. $T_{\mathrm{o}}$, onset temperature; $T_{\mathrm{p}}$, peak temperature; $T_{\mathrm{c}}$, conclusion temperature; $\Delta H$, enthalpy change. Average values of two measurements.

することが考えられる。また，炭素数 18 の二重結合をも つ不飽和脂肪酸の LPC (LPC-C $18 ： 1$, LPC-C 18：2）は, 同じ炭素数をもつ飽和脂肪酸の LPC-C $18: 0$ よりもアミ ロースと複合体を形成しにくいことが考えられる。

\section{DSC 測定}

LPC-アミロース複合体粉末(A)の DSC 測定結果を Table 2 に示した．脂質とアミロースの複合体は，DSC 測定にお いて吸熱カーブを示すことが報告されている ロース EX-1 は測定した温度範囲 $\left(30-130^{\circ} \mathrm{C}\right)$ で吸熱カー ブを示さなかった。 LPC は $37-52^{\circ} \mathrm{C}$ の温度範囲で吸熱 カーブを示した．炭素数 14 以上の脂肪酸をもつ LPC とア ミロース複合体の沈澱物の DSC カーブは, アミロース EX1 や各 LPC の DSC カーブとは異なり， $65-108^{\circ} \mathrm{C}$ の温度範 囲で吸熱カーブを示した。この結果から，これらの沈澱物 は複合体を形成していることが確認された。上清部のいず れの LPC とアミロースの混合粉末 (B)の DSC 測定に扔い ても，アミロース EX-1 と同様に吸熱カーブを示さなかっ た。これから，上清部の混合粉末 $(\mathrm{B}) に は$ 複合体は存在し ていないことが確認された。

飽和脂肪酸の LPC-アミロース複合体では，その構成脂 肪酸の炭素数が増加するに従って吸熱ピーク温度 $\left(T_{\mathrm{p}}\right)$ は, 高くなる傾向が認められたが, 融解熱のエンタルピー变化 $(\Delta H)$ は，逆に小さくなる傾向が認められた（Table 2). 炭素数 18 の LPC では，二重結合が増加すると吸熱ピーク 温度 $\left(T_{\mathrm{p}}\right)$ は低下し, 融解熱のエンタルピー变化 $(\Delta H)$ は増加する傾向がみられた（Table 2)，しかしながら，わ れわれが先に炭素数 18 の脂肪酸モノグリセリドのアミ ロース複合体について報告した結果では, 脂肪酸に二重結 合が存在すると吸熱ピーク温度 $\left(T_{\mathrm{p}}\right)$ は上昇し, 融解熱の エンタルピー変化 $(\Delta H)$ は減少することが観察され，本 結果と逆の関係がみられた"11.これらの吸熱ピーク温度 $\left(T_{\mathrm{p}}\right)$ や融解熱のエンタルピー变化 $(\Delta H)$ は，その脂質アミロース複合体からの脂質の解離や脂質の構造と関係が あると考えられるが詳細は不明である。

\section{HPAEC-PAD 分析}

HPAEC-PAD 分析によるAmylose EX-1の鎖長分布を Fig. 1 に示した。このアミロースは主成分 DP 11-14 から なる組成であり，Koizumi ら ${ }^{12}$ の結果とよく一致した。ま
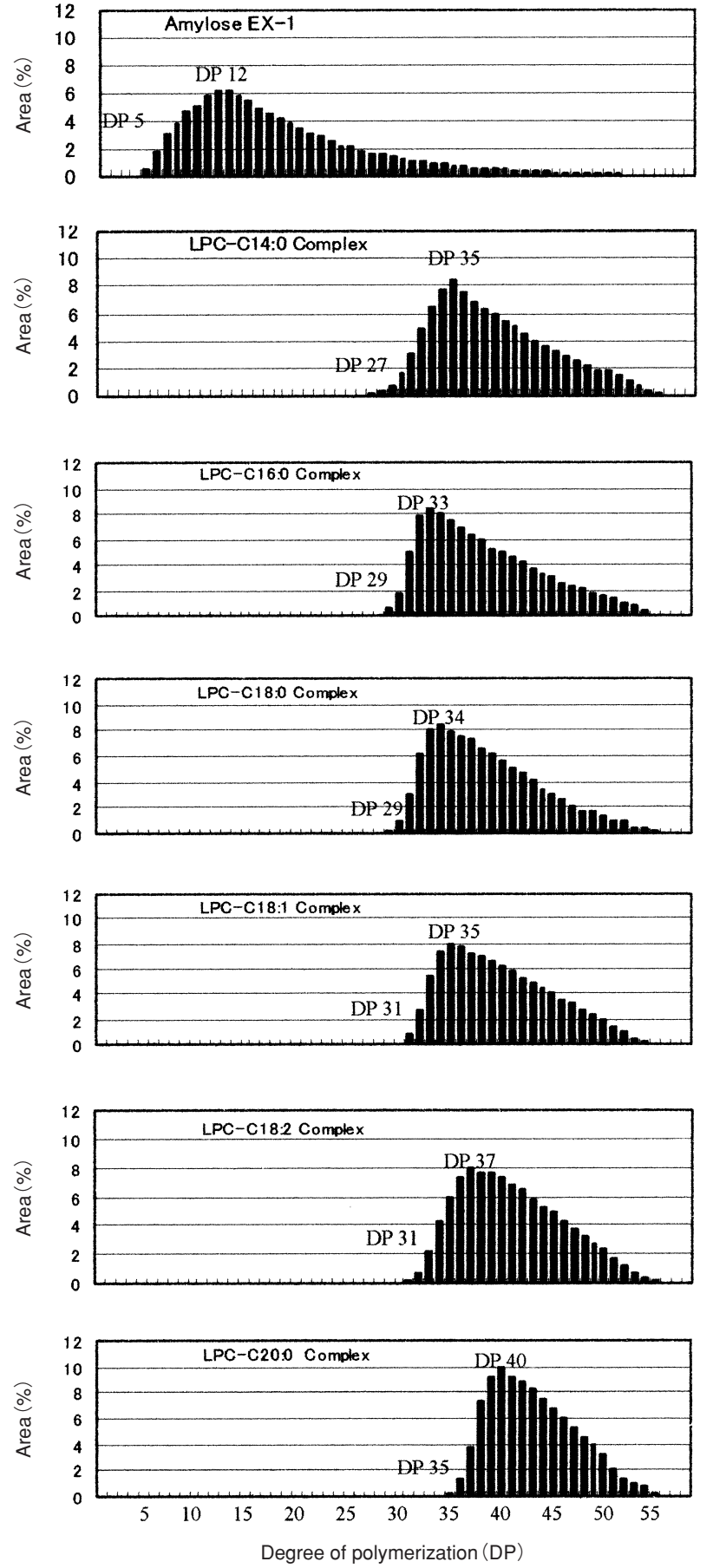

Fig. 1. HPAEC-PAD analysis of Amylose EX-1 and the amyloses in the precipitates formed by complexes using lysophosphatidylcholines.

た，沈澱物を凍結乾燥したLPC-アミロース複合体粉末 (A) を構成するアミロース鎖長の HPAEC-PAD 分析結果も Fig. 1 に示した. LPC が複合体を形成し始めるアミロース 重合度は, LPC-C 14：0, LPC-C 16：0, LPC-C 18：0, LPC-C $18 ： 1$, LPC-C $18 ： 2$, LPC-C $20 ： 0$ でそれぞれ 27 , 29，29，31，31，35であり，LPC の複合体を構成するお もなアミロース重合度は，それぞれ 34-36，32-34，3335，34-36，36-38，39-41 であった. 炭素数 14-20 の飽和 脂肪酸の LPC では，その複合体を形成し始めるアミロー 又重合度は，その脂肪酸の炭素数の増加とともにDP 27 から DP 35 と増加し, またその複合体を構成するおもな アミロース重合度も, その脂肪酸の炭素数の増加とともに 
増加する傾向にある。これは, LPCの脂肪酸部を包摂す るアミロースは, 複合体形成において脂肪酸の炭素数の増 加とともにグルコース残基が増加することを示している. 本実験で得られたLPC-C 16：0-アミロース複合体を構成 するおもなアミロース重合度（DP 32-34）は， M.C. Godet $ら^{6)}$ の推定したパルミチン酸の包接に要するアミロース重 合度 (DP 30-40) とほほ同程度と考えられる。 LPC-C 12：0アミロース複合体粉末 $(\mathrm{A})$ は, HPAEC-PAD 分析によって アミロースのピークが検出されなかったために，その構成 アミロース鎖長を求めることができなかった，LPC-C 12：0の複合体を構成するアミロース鎖長の解析には，さ らに詳細な検討が必要である。

Table 1 および Fig. 2 から, 飽和脂肪酸からなる LPC-C 18：0 が二重結合を有する不飽和脂肪酸の LPC-C $18 ： 1$ や LPC-C 18：2 よりも，アミロース EX-1 と複合体を形成し やすいことがわかった。このような複合体形成の特性は, われわれが先に炭素数 18 の脂肪酸モノグリセリドについ て報告した結果でも同様な傾向にあった ${ }^{11)}$. LPC-C 18：1 や LPC-C 18：2の包接に要するアミロースの鎖長は, そ の二重結合により屈曲した不飽和脂肪酸の構造の影響を受 けて, 飽和脂肪酸の LPC-C 18：0の包接よりもグルコー 不残基数が多く必要であると考えられる。

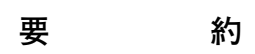

炭素数 10-20 の脂肪酸から構成される8 種類のリゾホス ファチジルコリンと $\overline{\mathrm{DP}} 18$ のアミロースの水溶液で複合

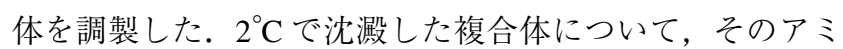
ロース鎖長を HPAEC-PAD で分析した. LPC-C 10：0はア ミロースと沈澱物を生成せず, 複合体が形成されなかっ た. LPC-C 12：0複合体を構成するアミロース鎖長は本 HPAEC-PAD 分析法では確定できなかった. LPCの複合体 を形成し始めるアミロース重合度は, LPC-C 14：0, LPCC $16 ： 0$, LPC-C $18: 0$, LPC-C $18 ： 1$, LPC-C $18: 2$, LPCC 20：0でそれぞれ 27，29，29，31，31，35であり，LPC
の複合体を構成するおもなアミロース重合度は，それぞれ 34-36，32-34，33-35，34-36，36-38，39-41であった。 これらの沈澱物はDSC 測定により複合体であることが確 認された.

\section{文献}

1 ）藤野安彦：穀物の脂質. 油化学, 32, 67-81 (1983).

2 ) S.L. Tan and W. Morrison: The distribution of lipids in the germ, endosperm, pericarp and tip cap of amylomaise, LG-11 hybrid maize and waxy maize. J. Am. Oil Chem. Soc., 56, 531535 (1979).

3 ) T. Riisom, N. Krog and J. Eriksen: Amylose complexing capacities of cis-and trans-unsaturated monoglycerides in relation to their functionality in bread. J. Cereal Sci., 2, 105-118 (1984).

4 ) S. Raphaelides and J. Karkalas: Thermal dissociation of amylose-fatty acid complexes. Carbohydr. Res., 172, 65-82 (1988).

5 ) J. Lagendijk and H.J. Pennings: Relation between complex formation of starch with monoglycerides and the firmness of bread. Cereal Sci. Today, 15, 354-365 (1970).

6 ) M.C. Godet, H. Bizot and A. Buleon: Crystallization of amylose-fatty acid complexes prepared with different amylose chain lengths. Carbohydr. Polym., 27, 47-52 (1995).

7 ) M.C. Godet, A. Buleon, V. Tran and P. Colonna: Structural features of fatty acid-amylose complexes. Carbohydr. Polym., 21, 91-95 (1993).

8 ) J. Karkalas and S. Raphaelides: Quantitative aspects of amyloselipid interaction. Carbohydr. Res., 157, 215-234 (1986).

$9)$ A. Neszmély, E. László and J. Holló : Biomolecular modelling: An interactive program for the visualization and modelling of carbohydrate (starch and oligosaccharide) complexes in solution. Starch/ Stärke, 39, 393-396 (1987).

10) M.C. Godet, V. Tran, M.M. Delage and A. Buleon: Molecular modelling of the specific interactions involved in the amylose complexation by fatty acids. Int. J. Biol. Macromol., 15, 11-16 (1993).

11) M. Yamashita, H. Adachi, T. Nakamura, H. Taniguchi, S. Onogi and M. Hisamatsu: Characteristics of amylose forming complexes with glycerol monooleate and monostearate. J. Appl. Glycosci., 50, 37-39 (2003).

12) K. Koizumi, T. Utamura and Y. Okada: Analysis of homogeneous D-gluco-oligosaccharides and -polysaccharides (degree of polymerization up to about 35) by high-performance liquid chromatography and thin-layer chromatography. J. Chromatogr., 321, 145-157 (1985). 